\title{
Spinal cord involvement of multiple myeloma detected by F-18 FDG PET/CT Scan
}

\section{F-18 FDG PET/CT tarama ile saptanan multiple myeloma'nın spinal kord tutulumu}

\author{
İlknur Ak Sivrikoz¹, Havva Üsküdar Teke², Zafer Gülbaş² \\ 'Department of Nuclear Medicine, Eskişehir Osmangazi University, School of Medicine, Eskişehir, Turkey \\ 2Department of Haematology, Eskişehir Osmangazi University, School of Medicine, Eskişehir, Turkey
}

F-18 2-fluoro-2-deoxy-D-glucose positron emission tomography/computed tomography (F-18 FDG $\mathrm{PET} / \mathrm{CT}$ ) images of a patient with spinal cord involvement of light chain (Lambda type) multiple myeloma (MM) is reported. A 56-year-old man had a 15-months history of light chain MM and have got out of hand after a chemotherapy regimen with only two cycles (melphalan, prednisone) was admitted to hospital because of weakness and lower back pain. To assess the systemic involvement of disease F-18 FDG PET/CT scan was performed. PET/CT images revealed a diffuse F-18 FDG uptake on spinal cord in the spinal canal along the thoracic 9th, 10th and 11th vertebrae (Fig 1). In addition, there were multiple active myeloma lesions and bone marrow involvement. At this time, bone marrow aspiration biopsy showed $30-50 \%$ of atypical plasma cells with a plasmablastic morphology (CD138 and CD56 positive by immune staining). Serum lactate dehydrogenase level was in normal range, alkaline phosphatase level was high (468 U/L). There was no plasma cell in peripheral blood smear. A lumbar puncture revealed a Cerebrospinal Fluid (CSF) content of 200 nucleated cells $/ \mu \mathrm{L}$. Flow cytometric analysis of CSF confirmed the spinal cord involvement of $\mathrm{MM}$, the percentage of both CD38 and CD138 positve cells was \%19.46 by flow cytometry (Fig 2). Although spinal cord involvement, there was no symptoms related spinal cord involvement such as limb weakness, paraparesis. To the best of our knowledge, it is the first report of spinal cord involvement of MM imaged by F-18 FDG PET/CT.

Extramedullary spread of MM may occur either at diagnosis or during the course of the disease. The involvement of central nervous system (CNS) occurs in approximately $1 \%$ of patients [1-3] and may present either with localized cerebral lesions or with meningeal myelomatosis, defined by the presence of monoclonal plasma cells in the CSF. The clinical presentation of CNS involvement include a wide set of neurological signs and symptoms, but headache, confusion, and limb weakness are the most common [3-5]. However, even in patients without circulating plasma cells, the haematogenous spread of their lymphoid progenitors has been postulated as a possible mechanism for CNS involvement [6].

Active myeloma is FDG-positive for focal and diffuse abnormalities. It has been reported that FDG 

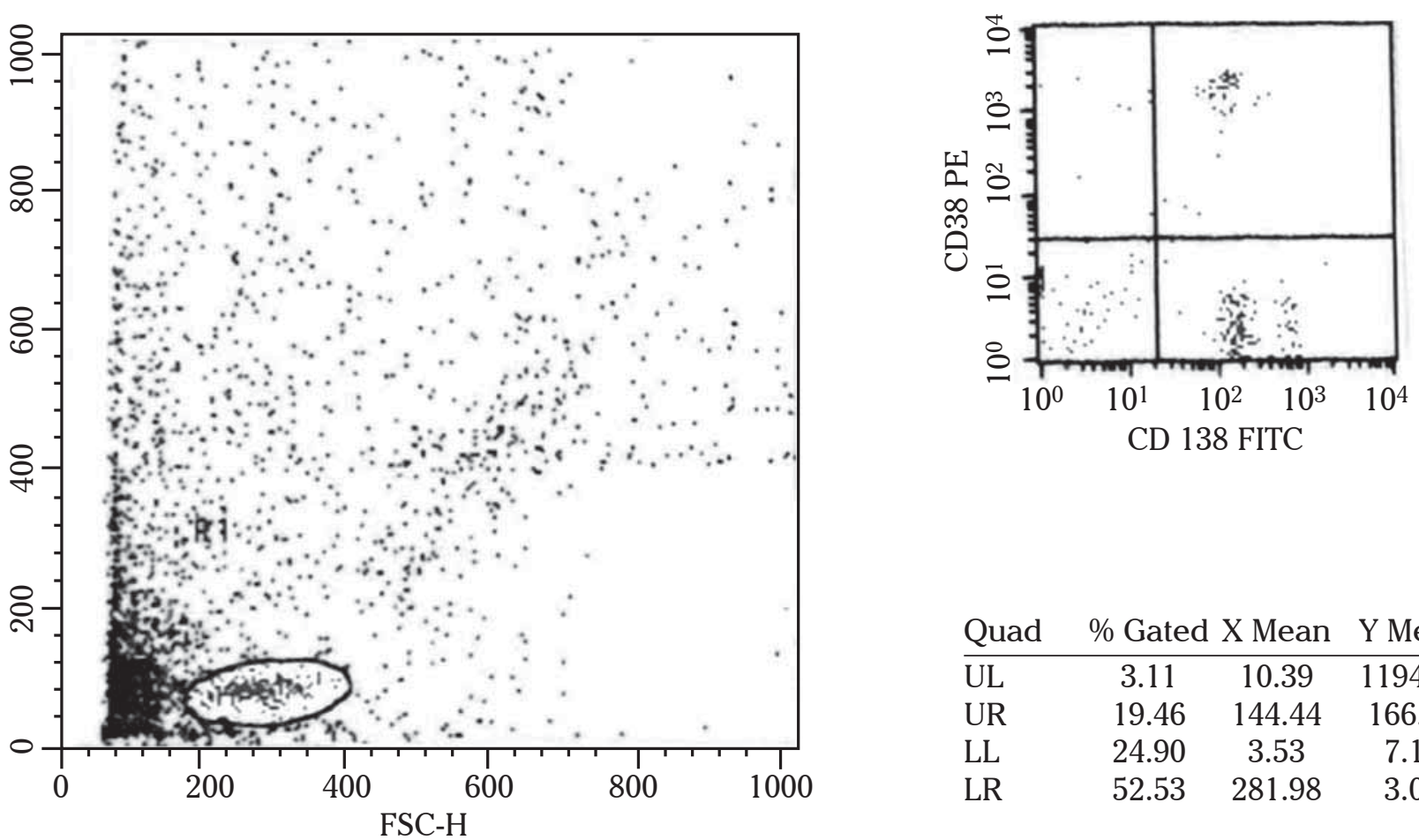

\begin{tabular}{lccc} 
Quad & \% Gated X Mean & Y Mean \\
\hline UL & 3.11 & 10.39 & 1194.91 \\
UR & 19.46 & 144.44 & 166.16 \\
LL & 24.90 & 3.53 & 7.18 \\
LR & 52.53 & 281.98 & 3.06
\end{tabular}

Figure 1. Three plane PET images (CT, PET and fused PET/CT in axial, sagittal and coronal projections) shows an intense F-18 FDG uptake with a maximum standard uptake value (SUVmax) of 5.7 in the thoracic 9th, 10th and 11th vertebrae and FDG avid masses in sternum and left $9^{\text {th }}$ rib

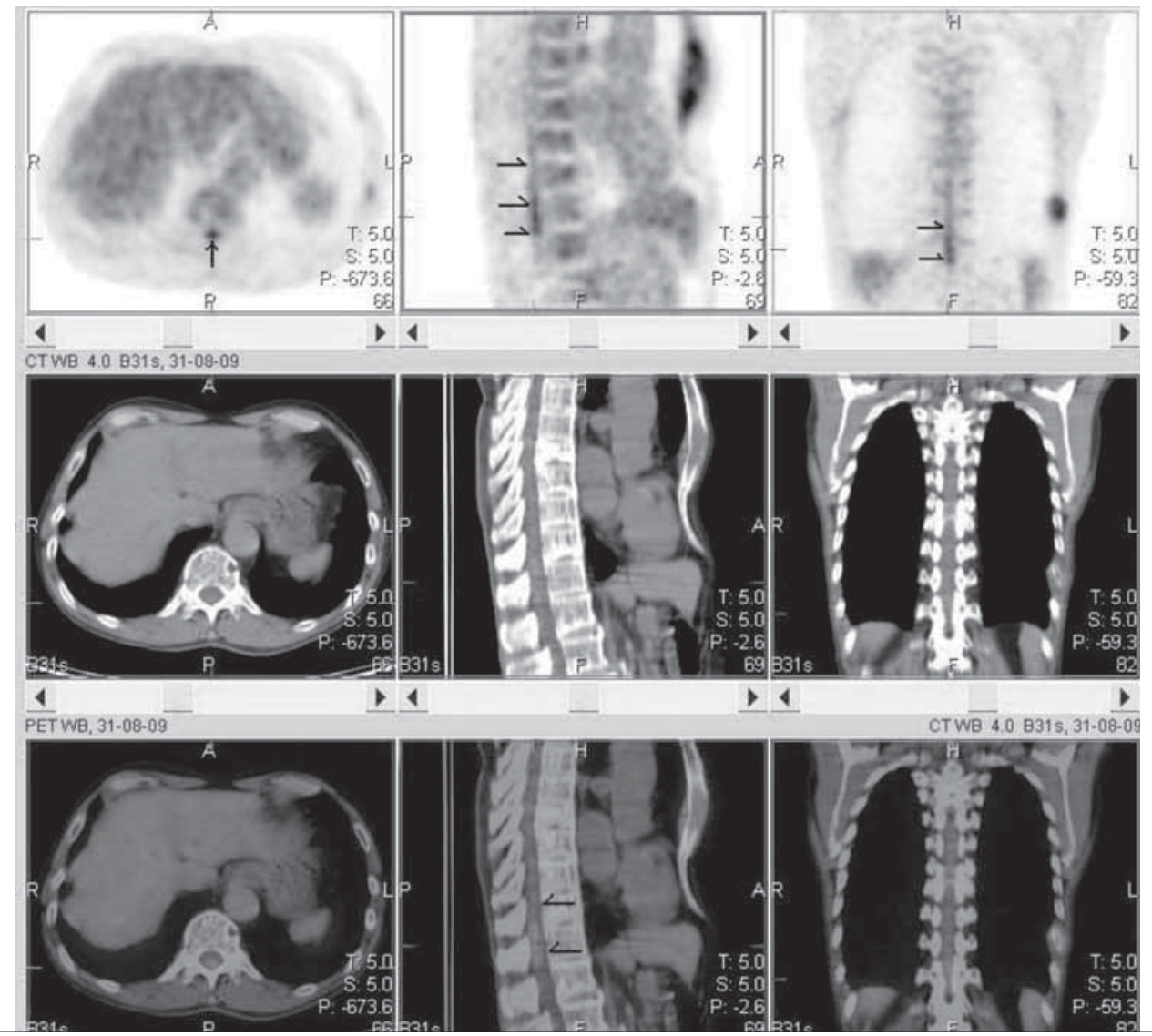

Figure 2. Flow cytometric analysis of CSF showing CD38 and CD 138 positive cells on upper riggt quadrant of the two-parameter histogram (\%19.46 of the cells) 
PET can significantly contribute to an accurate whole-body evaluation of multiple myeloma patients due to the ability to visualise highly energyconsuming cells such as tumour cells [7, 8]. In addition, the limited anatomical resolution of PET can be overcome by co-registration of functional PET images with morphological CT data with an integrated PET/CT system.

Written informed consent was obtained from the patient.

\section{Conflict of Interest}

No author of this paper has a conflict of interest, including specific financial interests, relationships, and/or affiliations relevant to the subject matter or materials included in this manuscript.

\section{References}

1. Beksaç M, Delforge M, Richardson P. The evolving treatment paradigm of multiple myeloma: From past to present and future. Turk J Hematol 2008;25:60-70.
2. Fassas AB, Ward S, Muwalla F, Van Hemert R, Schluterman K, Harik S, Tricot G. Myeloma of the central nervous system: strong association with unfavorable chromosomal abnormalities and other high-risk disease features. Leuk Lymphoma. 2004;45:291-300.

3. Nieuwenhuizen L, Biesma DH: Central nervous system myelomatosis: Review of the literature. Eur J Haematol. 2008;80:1-9

4. Petersen S, Wagner A, Gimsing P: Cerebral and meningeal multiple myeloma after autologous stem cell transplantation: A case report and review of the literature. Am J Hematol. 1999;62:228-33.

5. Patriarca F, Zaja F, Silvestri F, Sperotto A, Scalise A, Gigli G, Fanin R. Meningeal and cerebral involvement in multiple myeloma patients. Ann Hematol. 2001;80:758-62

6. Warner TF, Krueger RG: Circulating lymphocytes and the spread of myeloma: Review of the evidence. Lancet 3;1:1174-6.

7. Lütje S, de Rooy JW, Croockewit S, Koedam E, Oyen WJ, Raymakers RA. Role of radiography, MRI and FDGPET/CT in diagnosing, staging and therapeutical evaluation of patients with multiple myeloma. Ann Hematol. 2009;88:1161-8.

8. İlknur Ak, Zafer Gülbaş. Nuclear Medicine Applications in Hemato-Oncology. Turk J Hematol 2003;20:89-211.

\section{Obituary}

\section{Prof. Hüseyin Sipahioğlu (1925-2010)}

A Turkish hematologist, Professor Hüseyin Sipahioğlu, passed away September 11, 2010. He made several contributions to Turkish hematology including filiariasis, thalassemia, G6PD deficiency. In 1947, he graduated from İstanbul University Faculty of Medicine and had his Internal Medicine residency at Vakıf Gureba. He worked at Istanbul University and Kayseri Gevher Nesibe University Medical School, respectively. He was the dean of Gevher Nesibe Medical School between 1978-1980 and then he was the rector of Kayseri Erciyes University between 1980-1982. He retired in 1982. Sipahioğlu had over 200 published articles (14 international) and 5 printed books including his memories.

Nejat Akar, MD,Prof.

Ankara University, Turkey 